\title{
An uncommon polyp in the colon: a pedunculated cavernous hemangioma
}

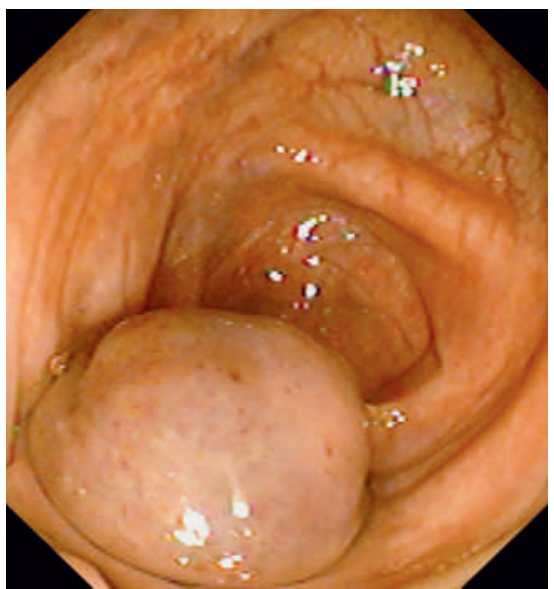

Fig. 1 Polyp with smooth surface located in transverse colon.

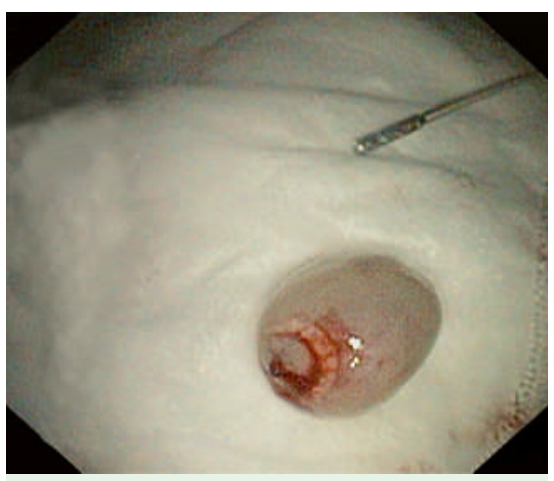

Fig. 2 Polyp after snare diathermy.

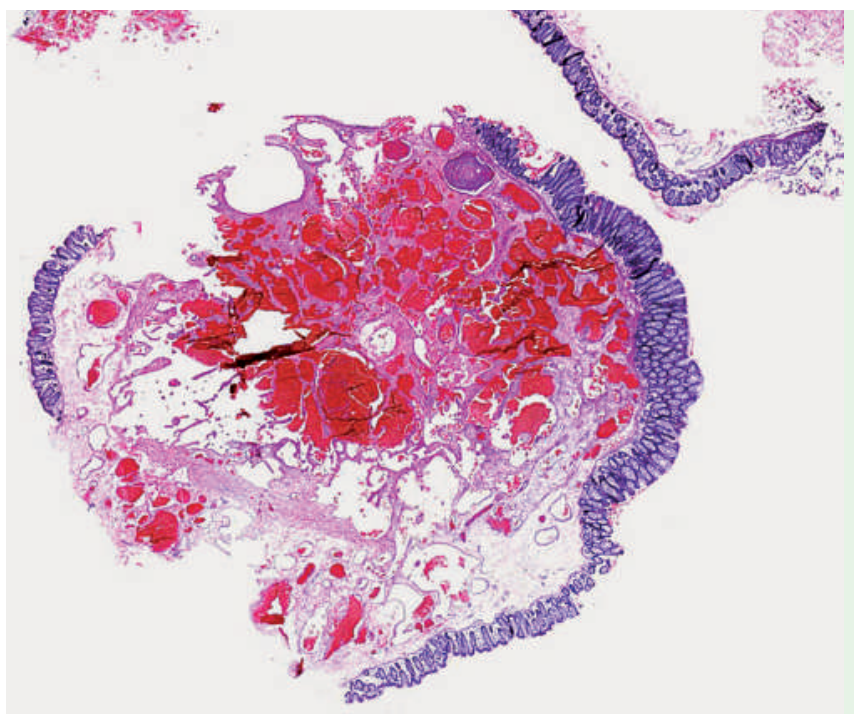

Colonoscopy was performed in a 40 -yearold man, who was referred by his primary care physician because of abdominal pain. This examination revealed a smooth, blue-colored polyp with a diameter of $30 \mathrm{~mm}$ on a long stalk, situated in the transverse colon ( $\bullet$ Fig. 1). There were no other abnormalities in the large intestine.

The polyp was successfully removed by snare polypectomy. There was no blood loss during the removal of the polyp, but once outside the patient the mass appeared to be filled with blood and emptied itself ( $\bullet$ Fig. 2 )

Histological examination showed a polyp with normal colonic mucosa at the surface and, underneath, in the submucosa, dilated vascular structures covered by endothelium without nuclear polymorphism. The vascular spaces were filled with blood. There were no signs of inflammation (๑ Fig. 3).

It was concluded that this was a pedunculated colonic polyp with cavernous hemangioma.

A PubMed search of the literature revealed three articles on colonic polyps with cavernous hemangioma [1-3], one of which was in Korean and was not ac-

Fig. 3 Histological section showing normal colonic mucosa at the surface and dilated vascular structures filled with blood (hematoxylin and eosin, original magnification $\times 40)$. cessible to us. The presenting complaints of the patients described in the other papers were rectal bleeding and pain. The polyps were removed by snare polypectomy without complications, as in the case of our patient.

Endoscopy_UCTN_Code_CCL_1AD_2AC

\section{T. B. M. van Deursen ${ }^{1}$, J. Buijs ${ }^{1}$, M. Nap ${ }^{2}$}

1 Department of Internal Medicine and Gastroenterology, Atrium Medical Center, Heerlen, The Netherlands

2 Department of Clinical Pathology, Atrium Medical Center, Heerlen, The Netherlands

\section{References}

1 Cho EY, Choi SC. The cavernous hemangioma of the colon inducing massive hematochezia and treated by endoscopic polypectomy. Korean J Gastroenterol 2005; 45: 379- 380

2 Liang LC, Forbes N, David J, Ozick L. Endoscopic polypectomy of an unusually long polypoid colorectal cavernous hemangioma. Gastrointest Endosc 1998; 47: 307-308

3 Amano K, Seko A, Nagura $K$ et al. A case of polypoid cavernous haemangioma of the sigmoid colon excised by colonoscopic polypectomy. Gastroenterol Jpn 1993; 28: $712-718$

Bibliography

DOI $10.1055 / \mathrm{s}-2007-995697$

Endoscopy 2008; 40: E127

(c) Georg Thieme Verlag KG Stuttgart · New York . ISSN 0013-726X

\section{Corresponding author}

\section{T. B. M. van Deursen, MD, PhD}

Department of Internal Medicine

and Gastroenterology

Atrium Medical Center

PO Box 4446

6401 CX Heerlen

The Netherlands

Fax: +31-45-5279477

C.vandeursen@atriummc.nl 